REFERENCES

1. M. L. Green, M. E. Gross, L. E. Papa, K. J. Schnoes, and D. Brasen, This Journal, 132, 2677 (1985).

2. L. Krusin-Elbaum, M. Wittmer, and D. S. Yee, Appl. Phys. Lett., 50, 1879 (1987).

3. Q. X. Jia, L. H. Chang, and W. A. Anderson, J. Mater. Res., 9, 2561 (1994).

4. H. N. Al-Shareef, K. R. Bellur, A. I. Kingon, and O. Auciello, Appl. Phys. Lett., 66, 239 (1995).

5. S. Y. Mar, J. S. Liang, C. Y. Sun, and Y. S. Huang, Thin Solid Films, 238, 158 (1994).

6. J. Si and S. B. Desu, J. Mater. Res., 8, 2644 (1993).

7. E. Kolawa, F. C. T. So, W. Flick, X. A. Shao, E. T.-S.
Pan, and M. A. Nicolet, Thin Solid Films, 173, 266 (1989).

8. T. S. Kalkur and Y. C. Lu, ibid., 205, 266 (1991).

9. B. D. Cullity, Elements of X-Ray Diffraction, 2 nd ed., Addison-Wesley Pub. Co., Reading, MA (1977).

10. A. Taylor, X-Ray Metallography, Wiley, New York (1961).

11. C. Barrett and T. B. Massalski, Structure of Metals, 3rd ed., McGraw Hill, New York (1966).

12. D. W. Shaw, Crystal Growth, p. 11, Plenum Press, London, (1974).

13. A. F. Mayadas and M. Shatzkes, Phys. Rev. B, 1, 1382 (1970).

\title{
Oxygen Exchange and Diffusion Coefficients of Strontium-Doped Lanthanum Ferrites by Electrical Conductivity Relaxation
}

\author{
J. E. ten Elshof, M. H. R. Lankhorst, and H. J. M. Bouwmeester \\ Laboratory of Inorganic Materials Science, University of Twente, 7500 AE Enschede, The Netherlands
}

\begin{abstract}
Electrical conductivity relaxation experiments were performed on thin specimens of $\mathrm{La}_{1-x} \mathrm{Sr}_{x} \mathrm{FeO}_{3-\delta}(x=0.1,0.4)$ at oxygen partial pressures $p_{O_{2}}=10^{-5}-1$ bar in the temperature range 923 to $1223 \mathrm{~K}$. The transient response of the electrical conductivity after a sudden change of the ambient oxygen partial pressure was analyzed in the frequency domain. The latter procedure allowed diffusion-limited and surface exchange-limited kinetics of re-equilibration to be distinguished. The response of specimens with thicknesses of 350 to $460 \mu \mathrm{m}$ indicated diffusion-controlled kinetics at $p_{\mathrm{O}_{2}}>$ 0.03 bar. The chemical diffusion coefficients, $\widetilde{D}$, were found invariant with oxygen pressure. At $1073 \mathrm{~K}$ the absolute values were $\widetilde{D}=6.5 \times 10^{-6} \mathrm{~cm}^{2} \mathrm{~s}^{-1}$ for $x=0.1$ and $\widetilde{D}=1.1 \times 10^{-5} \mathrm{~cm}^{2} \mathrm{~s}^{-1}$ for $x=0.4$, with activation energies of about $80 \mathrm{~kJ} / \mathrm{mol}$. The equilibration process was governed by surface exchange at $p_{\mathrm{O}_{2}}<0.01$ bar. The surface exchange coefficient, $k_{\mathrm{O}}$, was proportional to $p_{\mathrm{O}_{2}}^{n}$, where $n=0.65$ to 0.85 . This pressure dependency was interpreted in terms of a slow surface process involving an oxygen molecule and a surface oxygen vacancy, and causes the observed sharp transition from diffusion- to exchange-controlled kinetics. The activation energy of $k_{0}$ was estimated at 110 to $135 \mathrm{~kJ} / \mathrm{mol}$.
\end{abstract}

\section{Introduction}

Perovskite-type solid oxide solutions $\mathrm{La}_{1-x} \mathrm{Sr}_{x} \mathrm{FeO}_{3-\delta}$ are candidate materials for use as high temperature electrodes and oxygen separation membranes. In two recent papers, ${ }^{1,2}$ the oxygen permeation properties of dense $\mathrm{La}_{1-x} \mathrm{Sr}_{x} \mathrm{FeO}_{3-8}$ membranes were investigated under variation of oxygen partial pressure gradients. It was demonstrated that the surface exchange kinetics of oxygen play a rate-determining role under steady-state conditions in both air/He and air/CO, $\mathrm{CO}_{2}$ gradients, in particular at the oxygen lean side of the membrane. By exposing this side to a CO-containing atmosphere at high temperature, the surface exchange rate was significantly enhanced. Although the overall permeation rate remained exchange-limited in air/CO, $\mathrm{CO}_{2}$ gradients, diffusion became rate-determining in $\mathrm{O}_{2}$-containing atmospheres after exposure to $\mathrm{CO}$. A mechanism in which oxygen vacancies play a definite role was proposed for the exchange process in the presence of $\mathrm{CO}{ }^{2}$

Electrical conductivity relaxation experiments on cylindrical samples of $\mathrm{La}_{1-x} \mathrm{Ca}_{x} \mathrm{CrO}_{3-\delta}(x=0.1$ to 0.3$)$ in $\mathrm{CO}$, $\mathrm{CO}_{2}$ atmospheres by Yasuda and Hikita ${ }^{3}$ also indicated the involvement of oxygen vacancies in the exchange process. The same technique is applied to $\mathrm{La}_{1-x} \mathrm{Sr}_{x} \mathrm{FeO}_{3-8}$ in the present paper. In relaxation experiments, the time-dependent response of a physical property of the solid oxide is monitored, e.g., mass or electrical conductivity, after imposing a stepwise change of the chemical potential of molecular oxygen in the ambient. Although the most direct way to obtain information about oxygen diffusion and surface exchange is to measure its mass change, the measurement of electrical conductivity has the advantage of being more sensitive to variations in oxygen pressure. This requires that the concentrations of ionic and electronic defects are correlated, e.g., via the charge neutrality requirement. According to thermogravimetric analyses by Mizusaki et al. ${ }^{4}$ the defect chemistry of $\mathrm{La}_{1-x} \mathrm{Sr}_{x} \mathrm{FeO}_{3-\delta}$ can be modeled quantitatively in terms of two-point defect equilibria in a wide range of temperatures, oxygen partial pressures and strontium, doping levels. In Kröger-Vink notation $^{5}$ these defect reactions read

$$
\begin{gathered}
\frac{1}{2} \mathrm{O}_{2}+\mathrm{V}_{\mathrm{O}}^{\cdot *}+2 \mathrm{Fe}_{\mathrm{Fe}}^{x} \rightleftarrows \mathrm{O}_{\mathrm{O}}^{x}+2 \mathrm{Fe}_{\mathrm{Fe}}^{\cdot} \\
2 \mathrm{Fe}_{\mathrm{Fe}}^{x} \rightleftarrows \mathrm{Fe}_{\mathrm{Fe}}^{\cdot}+\mathrm{Fe}_{\mathrm{Fe}}^{\prime}
\end{gathered}
$$

Many studies employing the electrical conductivity relaxation technique have been reported covering a wide range of oxides, e.g., Ref. 6 to 12 . Whether the overall kinetics of re-equilibration after a step change is governed by surface exchange or diffusion depends on the geometry of the specimen under investigation. For any given geometry, a typical length $L_{\mathrm{d}}$, indicating the average distance across which transport of matter has to take place in order to equilibrate the entire specimen, can be identified. Diffusion-limited re-equilibration occurs when $L_{\mathrm{d}} \gg 1 / h,{ }^{13}$ with $h$ defined by

$$
h=\frac{k_{\mathrm{o}}}{D_{\mathrm{O}}}
$$

$D_{0}$ and $k_{\circ}$ and are the oxygen self-diffusion coefficient $\left(\mathrm{cm}^{2} / \mathrm{s}\right)$ and surface exchange coefficient $(\mathrm{cm} / \mathrm{s})$, respectively. Surface-controlled kinetics are encountered when 
the sample dimensions are decreased to such an extent that $L_{\mathrm{d}}<1 / h$.

In studies reported to date, the geometry of the specimen is usually chosen such as to ensure an overall rate limitation by diffusion. Moreover, it is generally assumed that the oxide interface equilibrates immediately with the newly imposed atmosphere, i.e., $k_{0}=\infty$. Several authors ${ }^{14-17}$ have pointed out that large systematic errors may have been caused in some of these studies by neglecting the surface exchange process.

The chemical diffusion coefficient $\tilde{D}$ is usually determined by fitting the time-dependent theoretical curve to the experimental data. The disadvantage of this approach is that bulk diffusion and (linear) surface kinetics cannot be distinguished easily, which may lead to misinterpretation of the nature of the re-equilibration process. In the frequency domain the two processes have quite different characteristics, and the analysis is not complicated if both are rate-limiting to more or less similar extents.

The aim of this study is to determine the relevant transport parameters of the perovskite-type oxide $\mathrm{La}_{1-x} \mathrm{Sr}_{x} \mathrm{FeO}_{3-\delta}$ (LSF) $(x=0.1,0.4)$, with emphasis on the investigation of the surface exchange kinetics. Thin dense specimens of perovskite material with large superficial surface areas are used to ensure one-dimensional diffusion with a small $L_{\mathrm{d}}$ value $(\approx 175$ to $230 \mu \mathrm{m})$. The chemical diffusion and surface exchange coefficients are determined from experimental data in the frequency domain assuming linear kinetic behavior for the surface exchange process.

\section{Theoretical Background}

Transient response to a stepwise change of gas-phase oxygen activity.-Consider a large plane sheet with sides $A$ and thickness $L(A>L)$ in chemical and thermal equilibrium with the surrounding atmosphere. The initial oxygen concentration in the solid is $c_{\mathrm{s}}$. At $t=0$, the oxygen activity in the ambient is changed stepwise to a new value which corresponds to a new equilibrium concentration, $c_{g}$, in the solid. Depending on the value of $c_{\mathrm{g}}$ relative to $c_{\mathrm{s}}$, oxygen starts to diffuse into or out of the solid via exchange with the gas phase. The oxygen concentration at a certain time, $t$, and position, $z(-1 / 2 L \leq z \leq 1 / 2 L)$, in the solid is given by $\mathrm{c}_{0}(z, t)$. The concentration $\mathrm{c}(z, t)$ is defined as

$$
c(z, t)=c_{\mathrm{o}}(z, t)-c_{\mathrm{s}}
$$

This concentration can be calculated by solving Fick's second law

$$
\frac{\partial c(z, t)}{\partial t}=\tilde{D} \frac{\partial^{2} c(z, t)}{\partial z^{2}}
$$

where $\tilde{D}$ is the chemical diffusion coefficient $\left(\mathrm{cm}^{2} \mathrm{~s}^{-1}\right)$. Assuming linear interface kinetics, the boundary conditions are

$$
\begin{array}{r}
-\left.\tilde{D} \frac{\partial \mathrm{c}(z, t)}{\partial z}\right|_{z=-\frac{1}{2} L}=K_{\mathrm{ex}}\left[c_{\mathrm{g}}-c_{\circ}\left(-\frac{1}{2} L, t\right)\right] \\
=K_{\mathrm{ex}}\left[\Delta c-c\left(-\frac{1}{2} L, t\right)\right] \\
-\left.\tilde{D} \frac{\partial \mathrm{c}(z, t)}{\partial z}\right|_{z=\frac{1}{2} L}=-K_{\mathrm{ex}}\left[\mathrm{c}_{\mathrm{g}}-\mathrm{c}_{\mathrm{O}}\left(\frac{1}{2} L, t\right)\right] \\
=-K_{\mathrm{ex}}\left[\Delta c-c\left(\frac{1}{2} L, t\right)\right]
\end{array}
$$

$K_{\text {ex }}\left(\mathrm{cm} \mathrm{s}^{-1}\right)$ is the apparent surface exchange coefficient, and $\Delta \mathrm{c} \equiv \mathrm{c}_{\mathrm{g}}-\mathrm{c}_{\mathrm{s}}$. Fick's law is solved in the Laplace domain. The Laplace transform $\mathrm{L}[f(t)]=\overline{f(s)}$ of Eq. 5 reads

$$
s \overline{c(z, s)}=\tilde{D} \frac{\partial^{2} \overline{c(z, s)}}{\partial z^{2}}
$$

which has as a general solution

$$
\overline{c(z, s)}=A e^{\mathrm{k} z}+B e^{-\mathrm{k} z}
$$

where $k=\sqrt{s / \tilde{D}}$. The Laplace transforms of the boundary conditions 6 and 7 are

$$
\begin{array}{r}
-\left.\tilde{D} \frac{\partial \overline{c(z, s)}}{\partial z}\right|_{z=-\frac{1}{2} L}=K_{\mathrm{ex}}\left[\overline{\Delta c}-\overline{c\left(-\frac{1}{2} L, s\right)}\right] \\
=K_{\mathrm{ex}}\left[\frac{\Delta c}{s}-\overline{c\left(-\frac{1}{2} L, s\right)}\right] \\
-\left.\tilde{D} \frac{\partial \overline{c(z, s)}}{\partial z}\right|_{z=\frac{1}{2} L}=-K_{\mathrm{ex}}\left[\overline{\Delta c}-\overline{c\left(\frac{1}{2} L, s\right)}\right] \\
=-K_{\mathrm{ex}}\left[\frac{\Delta c}{s}-\overline{c\left(\frac{1}{2} L, s\right)}\right]
\end{array}
$$

Inserting Eq. 9 into the Eq. 10 and 11 yields the values $A$ and $B$, and back substitution results in

$$
\overline{c(z, s)}=\frac{1}{1+\frac{k \tilde{D}}{K_{\mathrm{ex}}} \tanh \left(\frac{1}{2} k L\right)} \overline{\Delta c} \frac{\cosh (k z)}{\cosh \left(\frac{1}{2} k L\right)}
$$

In the time domain, the total mass change of the specimen is

$$
m(t)=A^{2} M_{\circ} \int_{-1 / 2 L}^{1 / 2 L} c(z, t) d z
$$

with $M_{0}$ the atomic mass of oxygen. The Laplace transform of the relative mass change $m(t) / m(\infty)$ is then expressed by

$$
\begin{aligned}
\frac{\overline{m(s)}}{m(\infty)}= & \frac{1}{L \Delta c} \int_{-1 / 2 L}^{1 / 2 L} \overline{c(z, s)} d z \\
& =\frac{1}{1+\frac{k \tilde{D}}{K_{\mathrm{ex}}} \tanh \left(\frac{1}{2} k L\right)}\left(\frac{2}{s k L}\right) \tanh \left(\frac{1}{2} k L\right)
\end{aligned}
$$

Relationship between electrical conductivity and mass change.-The mass change of a $\mathrm{La}_{1-x} \mathrm{Sr}_{x} \mathrm{FeO}_{3-8}$ specimen can be related to its electrical conductivity change via the charge neutrality requirement

$$
\left[e^{\prime}\right]+\left[\mathrm{Sr}_{\mathrm{La}}^{\prime}\right]=\left[h^{*}\right]+2\left[\mathrm{~V}_{\circ}^{* *}\right]
$$

where $[e]$ is the concentration of $\mathrm{Fe}^{2+}\left(\mathrm{Fe}_{\mathrm{Fe}}^{\prime}\right)$ and $\left[h^{*}\right]$ the $\mathrm{Fe}^{4+}$ concentration $\left(\mathrm{Fe}_{\mathrm{Fe}}^{*}\right)$. Under the conditions covered by the experiments described, i.e., at sufficiently high values of $p_{\mathrm{O}_{2}}$, it can be assumed safely that $[e] \ll\left[\mathrm{Sr}_{\mathrm{La}}^{\prime}\right],\left[h^{\circ}\right],\left[\mathrm{V}_{\circ}^{* *}\right]$. Since $\left[\mathrm{Sr}_{\mathrm{La}}^{\prime}\right]=x$ is constant, any local change of the oxygen vacancy concentration is then linearly related to the accompanying electron hole concentration change

$$
\frac{\left[h^{*}(z, t)\right]-\left[h^{*}(z, 0)\right]}{\left[h^{*}(z, \infty)\right]-\left[h^{\bullet}(z, 0)\right]}=\frac{\left[\mathrm{V}_{\circ}^{* *}(z, t)\right]-\left[\mathrm{V}_{\circ}^{* *}(z, 0)\right]}{\left[\mathrm{V}_{\circ}^{* *}(z, \infty)\right]-\left[\mathrm{V}_{\circ}^{* *}(z, 0)\right]}
$$

The local electron hole conductivity $\sigma_{\mathrm{h}}(z, t)\left(\Omega^{-1} \mathrm{~m}^{-1}\right)$ is defined by $\sigma_{h}(z, t)=q_{\mathrm{h}} \mu[h(z, t)]$, with $q_{\mathrm{h}}$ the hole charge $(C)$ and $\mu$ the hole mobility $\left(\mathrm{cm}^{2} \mathrm{~V}^{-1} \mathrm{~s}^{-1}\right)$. The apparent conductivity $\sigma_{\text {app }}(t)$ on a macroscopic scale is measured perpendicularly to the direction in which the net oxygen transport occurs. It can be shown ${ }^{3}$ that the following proportionality holds

$$
\sigma_{\text {app }}(t)=\frac{1}{L} \int_{-1 / 2 L}^{1 / 2 L} \sigma_{h}(z, t) d z
$$

The relative mass change $m(t) / m(\infty)$ of the specimen can be related to the relative average change of the oxygen vacancy concentration 


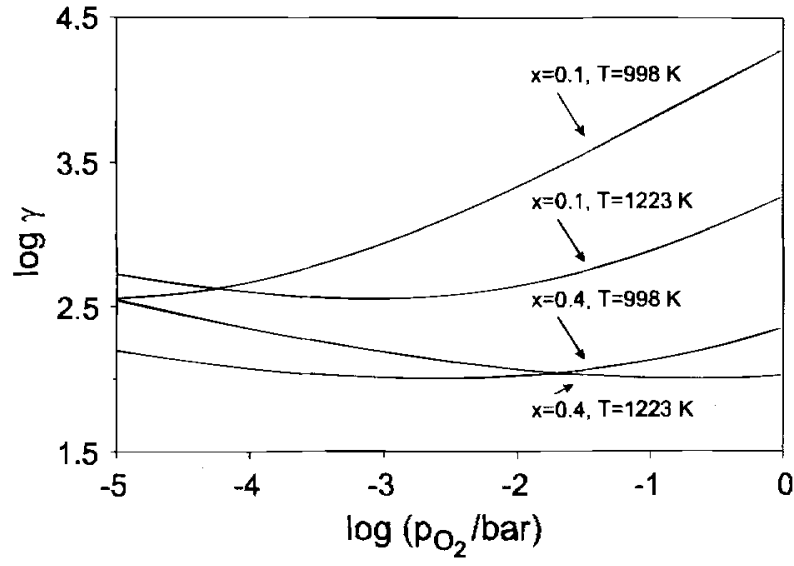

Fig. 1. Thermodynamic enhancement factors of $\mathrm{La}_{1-x} \mathrm{Sr}_{x} \mathrm{FeO}_{3-8}$ $(x=0.1,0.4)$ at 998 and $1223 \mathrm{~K}$.

$$
\frac{m(t)}{m(\infty)}=\frac{1}{L} \int_{-1 / 2 L}^{1 / 2 L} \frac{\left[\mathrm{V}_{O}^{\bullet \bullet}\right](z, t)-\left[\mathrm{V}_{\circ}^{\bullet \bullet}\right](z, \infty)-\left[\mathrm{V}_{\circ}^{* *}\right](z, 0)}{[z, \infty)} d z
$$

Combination of Eq. 16, 17, and 18 and Laplace transformation leads to

$$
\overline{\sigma_{\text {app }}^{\text {rel }}(s)}=\mathrm{L}\left(\frac{\sigma_{\text {app }}(t)-\sigma_{\text {app }}(0)}{\sigma_{\text {app }}(\infty)-\sigma_{\text {app }}(0)}\right)=\frac{\overline{m(s)}}{m(\infty)}
$$

Diffusion coefficients and surface exchange coefficients.-The oxygen self-diffusion coefficient, $D_{0}$, is related to the chemical diffusion coefficient, $\widetilde{D}$, via the thermodynamic factor, $\gamma^{18}$

$$
\gamma=\frac{1}{R T} \frac{\partial \mu_{\mathrm{o}}}{\partial \ln c_{\mathrm{o}}}=\frac{\tilde{D}}{D_{\mathrm{o}}}
$$

$\mu_{\mathrm{O}}$ is the chemical potential of atomic oxygen, $\mu_{0}=\mu_{0}^{0}+$ $R T \ln \sqrt{p_{\mathrm{O}_{2}}}$. Thus

$$
\gamma=\frac{1}{2} \frac{\partial \ln p_{\mathrm{O}_{2}}}{\partial \ln c_{\mathrm{o}}}
$$

Since the diffusion of oxygen is physically equal to that of oxygen vacancies in the opposite direction, the vacancy diffusion coefficient, $D_{v}$, can be calculated using the relationship $D_{\mathrm{O}} \mathrm{c}_{\mathrm{O}}=D_{\mathrm{v}} \mathrm{c}_{\mathrm{v}}$, where $c_{\mathrm{v}}$ is the oxygen vacancy concentration.

$K_{\text {ex }}$ is defined in a purely empirical manner by Eq. 6 and 7. Its value cannot be related $a$ priori to the thermodynamics of the system under investigation. The oxygen flux expressed in terms of a small chemical potential difference $\Delta \mu_{0}=\mu_{\mathrm{s}}-\mu_{\mathrm{g}}$ between surface and gas phase reads ${ }^{19}$

$$
j_{\mathrm{O}}=-\frac{k_{\mathrm{O}} c_{\mathrm{O}}}{R T} \Delta \mu_{\mathrm{O}}
$$

Here $k_{\mathrm{O}}$ is the surface exchange coefficient as determined from measurements performed in thermodynamic equilibrium, e.g., ${ }^{18} \mathrm{O} /{ }^{16} \mathrm{O}$ isotopic exchange. Combination of Eq. 7 and 22 leads to

$$
K_{\text {ex }}=\frac{k_{\mathrm{o}} c_{\mathrm{o}}}{R T} \frac{\Delta \mu_{\mathrm{O}}}{\Delta c_{\mathrm{o}}} \approx k_{\mathrm{o}} \gamma
$$

The defect concentrations in LSF can be calculated from thermogravimetric measurements ${ }^{4}$ as discussed in detail elsewhere. ${ }^{1}$ The thermodynamic factors, $\gamma$, of $\mathrm{La}_{1-x} \mathrm{Sr}_{x} \mathrm{FeO}_{3-\delta}$ at a few selected temperatures calculated from these results are illustrated in Fig. 1.

\section{Experimental}

The experimental setup is shown in Fig. 2. Oxygen $\left(\mathrm{O}_{2}\right.$ $5.0)$ diluted in nitrogen $\left(\mathrm{N}_{2}, 5.0\right)$ was used for re-equilibration of the sample in gas atmospheres with oxygen pressures of 0.01 to 1.0 bar. Remaining traces of water were stripped from the incoming gas streams to concentrations $<0.5 \mathrm{ppm}$ using molsieve $4 \mathrm{~A}$-based moisture filters. Two separate gas streams with flows of $100 \mathrm{ml} / \mathrm{min}$ STP (standard temperature, pressure) were imposed by Brooks $5850 \mathrm{E}$ mass flow controllers. Homemade yttria stabilized zirconia-based oxygen pumps were used for pumping small amounts of oxygen into either one of the nitrogen streams, yielding concentrations in the range 3 to $2800 \mathrm{ppm} \mathrm{O}_{2}$. One of the gas flows was fed to a quartz sample tube which was placed inside a furnace, while the other flow was vented. With a fast electrical four-way valve, the flows leading to the sample furnace and the vent could be interchanged, thus making a stepwise change of the gas atmosphere in the sample tube. The oxygen concentrations in both gas streams were measured by an oxygen sensor (Systech ZR893/4). In Fig. 3 the response of the oxygen sensor to a step change of 60 to $25 \mathrm{ppm} \mathrm{O}_{2}$ is shown. Oxygen pressure steps were performed in oxidizing or reducing direction in which the $p_{\mathrm{O}_{3}}$ was varied with a factor of 5 (at high $p_{\mathrm{O}_{2}}$ ) or smaller, typically below 3.3. To avoid mass-transfer limitations, oxidation runs were performed only at a final oxygen concentration of $900 \mathrm{ppm}$ or more.

The method of preparation of the samples is described extensively elsewhere. ${ }^{1}$ The dimensions of the rectangular samples were $27 \times 14 \times 0.36$ to $0.46 \mathrm{~mm}$, with densities 93.5 to $94.5 \%$ for $\mathrm{La}_{0.6} \mathrm{Sr}_{0.4} \mathrm{FeO}_{3-8}$ and 97.5 to $98.0 \%$ for $\mathrm{La}_{0.9} \mathrm{Sr}_{0,1} \mathrm{FeO}_{3-8}$ relative to theoretical. The specimen surfaces were polished with $1000 \mathrm{MESH} \mathrm{SiC}$ and ultrasonically cleaned in alcohol prior to use.

Electrical contacts were made by winding gold wire $(0.1 \mathrm{~mm}$ diam) around the outer ends of the samples. Gold paste (Blythe Colours B.V., The Netherlands) was used to improve the contacts between wires and specimen. Gold

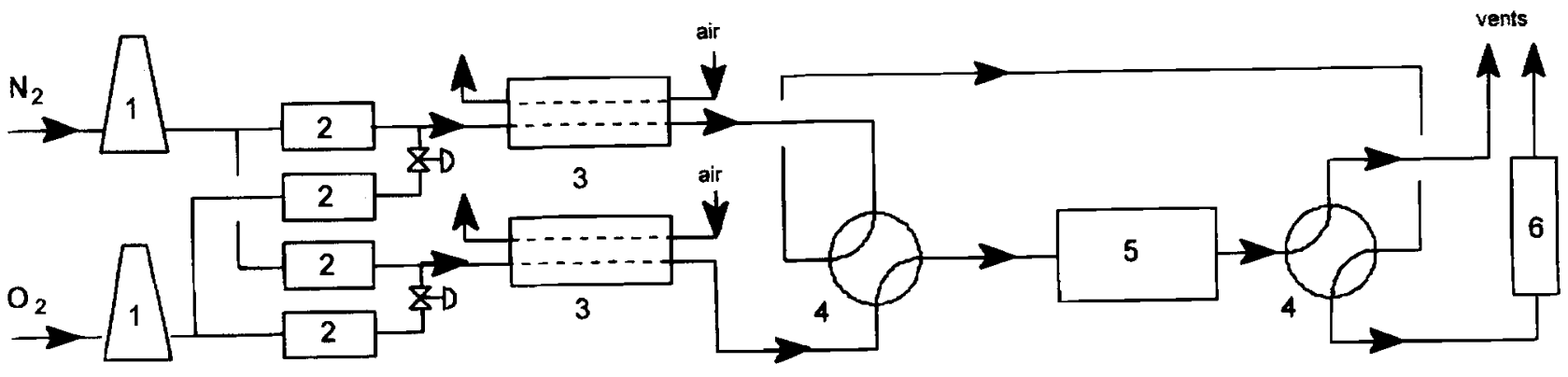

$1=$ Water absorber

$2=$ Mass flow controller
$3=$ Oxygen pump

$4=$ Four-way valve
$5=$ Sample furnace

$6=$ Oxygen sensor

Fig. 2. Schematic diagram of the experimental setup. 


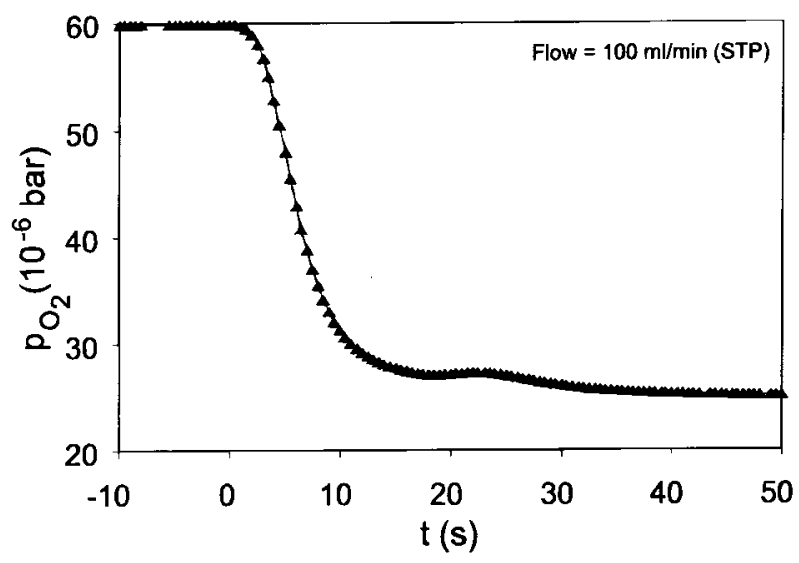

Fig. 3. Oxygen sensor response after stepwise change of the oxygen partial pressure in the specimen compartment.

was chosen since it is known to be rather inactive in the exchange of oxygen.

The specimen resistance was measured in a Wheatstone bridge. A function generator was used to impose an ac voltage, $V$, across the bridge. The outgoing signal was measured with reference to $V$ by a lock-in amplifier (EG\&G Princeton Applied Research 129A), and logged with sampling rates of 0.01 to $1000 \mathrm{~Hz}$. To determine $K_{\mathrm{ex}}$ and/or $\tilde{D}$, the function $Z(s)$, given by

$$
\begin{aligned}
\overline{Z(s)}=\frac{1}{s^{2} \overline{\sigma_{\mathrm{app}}^{\mathrm{rel}}(s)}=} & \frac{L}{2 K_{\mathrm{ex}}} \\
& +\sqrt{\frac{L^{2}}{4 \tilde{D} s}} \operatorname{coth}\left(\frac{1}{2} k L\right)=R+T(s)
\end{aligned}
$$

was calculated from the data and analyzed using Equivalent Circuit software ${ }^{20}$ by fitting $\overline{Z(j \omega)}$ to a serial electrical circuit consisting of a resistance, $R$ (representing the surface reaction), and/or a cotangent-hyperbolic function, $T$ (representing a finite length diffusion element).

\section{Results and Discussion}

Impedance representations of some experimental data $\overline{Z(j \omega)}=-1 / \omega^{2} \overline{\sigma_{\mathrm{app}}^{\text {rel }}(j \omega)}$ are shown in Fig. 4. It was observed that the times necessary to re-equilibrate the samples were more or less the same in the oxygen partial pressure range 0.03 to 1 bar $\mathrm{O}_{2}$. Results from an oxygen partial pressure step from 0.03 to $0.0997 \mathrm{bar}$ on $\mathrm{La}_{0.9} \mathrm{Sr}_{0.1} \mathrm{FeO}_{3-\delta}$ at $998 \mathrm{~K}$ are given in Fig. 4a.

Since the entire impedance spectrum is determined from a single relaxation curve, the scatter in the high-frequency data is inherent to the method of measurement. More detailed analysis of this region is possible only upon direct application of complex impedance spectroscopy, i.e., by determining the response at each frequency individually. It is feasible to attribute the high-frequency behavior to the effect of diffusion. The finite diffusion element $T(j \omega)$ in Eq. 24 gives a fair description of the experimental response curve. The absence of a real axis offset in the high-frequency limit of the data indicates the absence of the influence of a surface reaction (represented by the element $R$ ). Purely bulk-controlled kinetics are therefore assumed in the best fit of Eq. 24 to the data, indicated by the drawn line in Fig. 4a. The re-equilibration kinetics above $10^{-2}$ bar $\mathrm{O}_{2}$ were found to be fully determined by diffusion in general.

At oxygen partial pressures below about $10^{-2}$ bar, the reequilibration times increased strongly with decreasing oxygen partial pressure. This cannot be attributed to mass-transfer limitations in the gas phase due to the thermally activated nature of the re-equilibration process under these conditions. An impedance representation of data obtained in the low oxygen pressure range is shown in Fig. 4b. In comparison with the data in Fig. 4a, the real

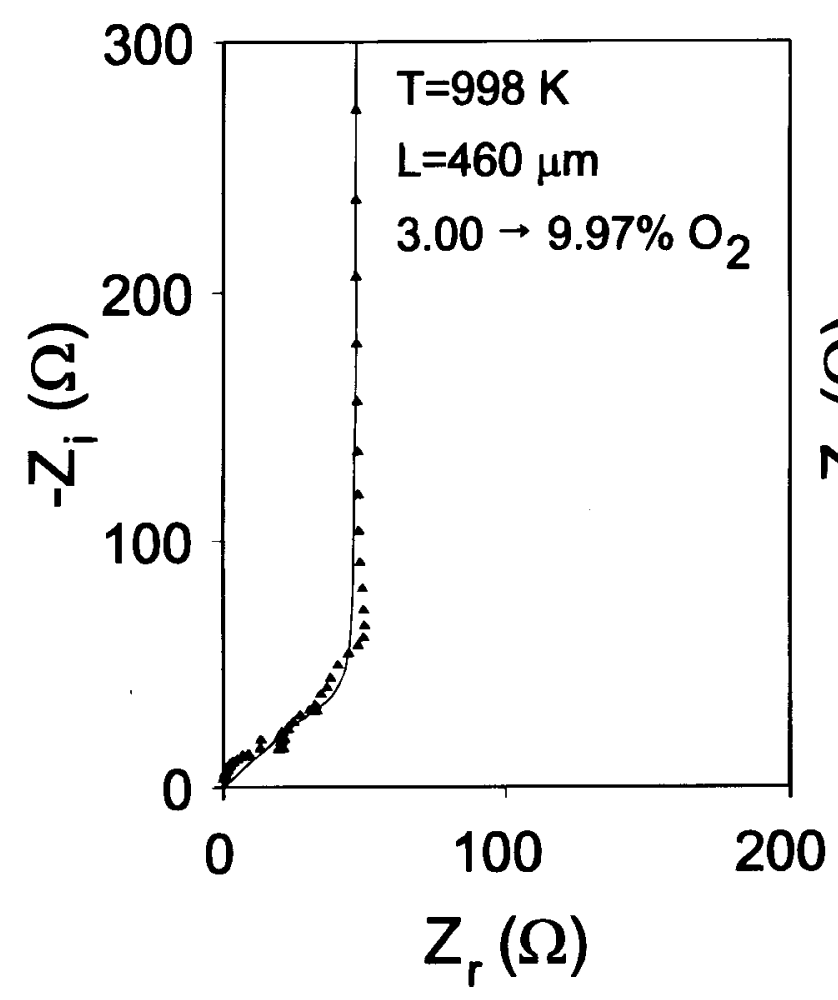

a.

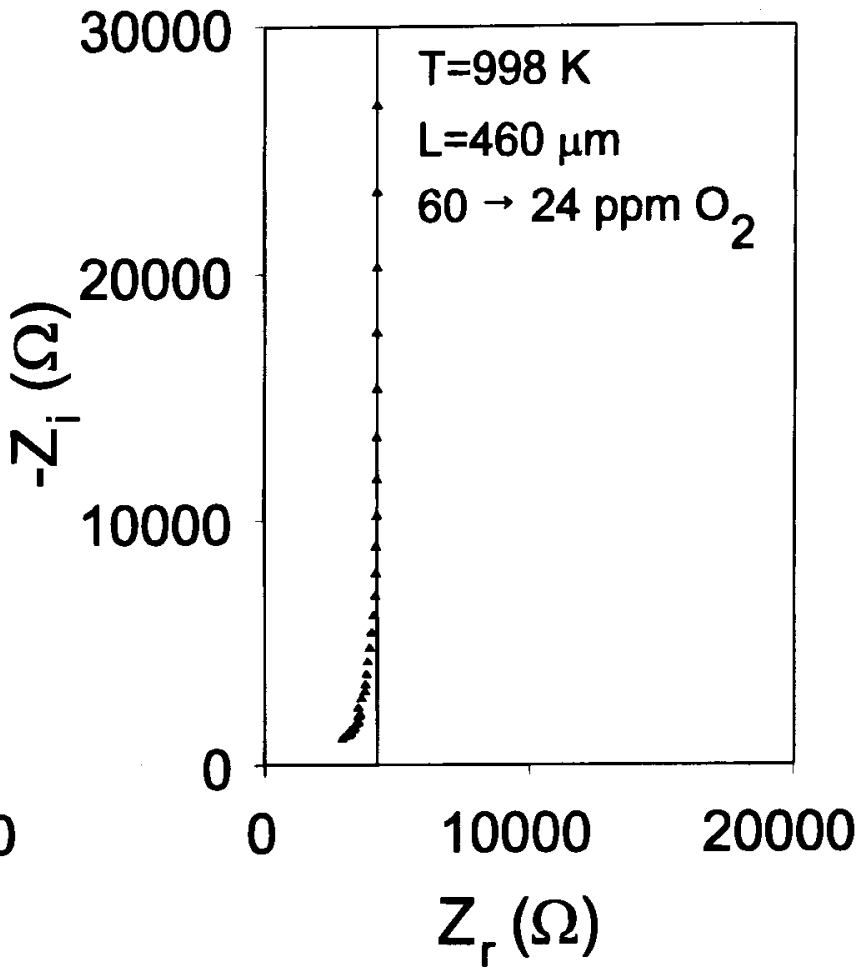

b.

Fig. 4. Impedance representations of transient electrical conductivity of $\mathrm{La}_{0.9} \mathrm{Sr}_{0.1} \mathrm{FeO}_{3-8}:$ (a) diffusion-limited re-equilibration and (b) surface-exchange-limited re-equilibration. Best fits to Eq. 24 are indicated by lines. 
part of $\overline{Z(j \omega)}$ has a much larger value. The deviation from a straight line at high frequency cannot be explained in terms of finite diffusion behavior, since the absolute value of the deviation is too large. The data are therefore interpreted in terms of a surface resistance, $R$, only, as assumed in the best fit to the low-frequency data, indicated by the line in Fig. 4b. The deviation from linearity at high frequency can be understood by considering that the re-equilibration times, attributed to $R$ in our interpretation, increased strongly with decreasing oxygen pressure. This will result in considerable changes of $R$ in the course of a re-equilibration run, in particular in the initial stages.

The example illustrated in Fig. 4b was typical for oxygen pressure steps in reducing direction. The observation that spectra from oxygen pressure steps in oxidizing direction showed the real part of the impedance to increase at higher frequencies further supports our interpretation. Hence, all re-equilibration experiments below $p_{O}=$ $10^{-2}$ bar were interpreted in terms of exchange-controlled kinetics.

In the $p_{\mathrm{O}_{2}}$ range of 0.01 to $0.10 \mathrm{bar}$, mixed diffusion/exchange-controlled kinetics were observed. It was difficult to separate these two processes properly, which is mainly due to the strong oxygen pressure dependence of $K_{\text {ex }}$. As this dependence is reflected in nonlinear behavior at high frequencies, the high-frequency behavior characterizing diffusion cannot be distinguished easily.

Chemical diffusion coefficients $D$ and surface exchange coefficients $K_{\mathrm{ex}}$ were determined from $T$ and $R$, respectively. No systematic differences were observed between the values of transport coefficients determined from oxidation and reduction runs when the results were assigned to the final oxygen pressure in the specimen compartment.

Diffusion coefficients.-No pressure dependence of $\tilde{D}$ could be observed within experimental error, as illustrated in Fig. 5 for $\mathrm{La}_{0.9} \mathrm{Sr}_{0.1} \mathrm{FeO}_{3-\delta}$. The Arrhenius curves are shown in Fig. 6 . The calculated activation energies of $\tilde{D}$ are $82 \pm 7 \mathrm{~kJ} / \mathrm{mol}$ for $\mathrm{La}_{0.9} \mathrm{Sr}_{0.1} \mathrm{FeO}_{3-\delta}$ and $81 \pm 12 \mathrm{~kJ} / \mathrm{mol}$ for $\mathrm{La}_{0.6} \mathrm{Sr}_{0.4} \mathrm{FeO}_{3-\delta}$. Average values of $\widetilde{D}$ obtained at various temperatures are listed in Table I, where the corresponding oxygen vacancy diffusion coefficients, $D_{\mathrm{v}}$, are also given. Ishigaki et al ${ }^{21}$ obtained a value $D_{\mathrm{v}}=1.95 \times$ $10^{-5} \mathrm{~cm}^{2} \mathrm{~s}^{-1}$ from ${ }^{18} \mathrm{O} /{ }^{16} \mathrm{O}$ isotopic exchange on single crystals $\mathrm{La}_{0.6} \mathrm{Sr}_{0.4} \mathrm{FeO}_{3-\delta}$ at $1273 \mathrm{~K}$, and a vacancy diffusion coefficient of 0.8 to $0.9 \times 10^{-5} \mathrm{~cm}^{2} \mathrm{~s}^{-1}$ was calculated from oxygen fluxes through dense membranes at $1273 \mathrm{~K}$. Extrapolation of the present results to $1273 \mathrm{~K}$ yields $D_{\mathrm{v}}=$ 1.7 to $2.0 \times 10^{-5} \mathrm{~cm}^{2} \mathrm{~s}^{-1}$, which is reasonably close.

There is also reasonable agreement with existing data in literature for $\mathrm{La}_{0.9} \mathrm{Sr}_{0.1} \mathrm{FeO}_{3-\delta}$. A vacancy diffusion coefficient of $4.6 \times 10^{-6} \mathrm{~cm}^{2} \mathrm{~s}^{-1}$ was reported for single-crystalline material at $1223 \mathrm{~K},{ }^{21}$ and oxygen permeation measurements yielded $5.7 \times 10^{-6} \mathrm{~cm}^{2} \mathrm{~s}^{-1}$ for polycrys-

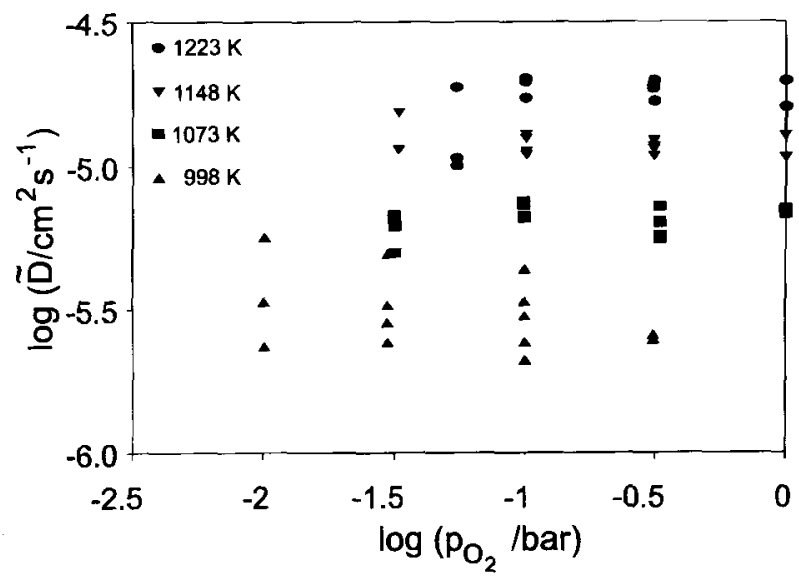

Fig. 5. Chemical diffusion coefficient of $\mathrm{La}_{0.9} \mathrm{Sr}_{0.1} \mathrm{FeO}_{3-\delta} v s$. $\mathrm{PO}_{2}$ at several temperatures.

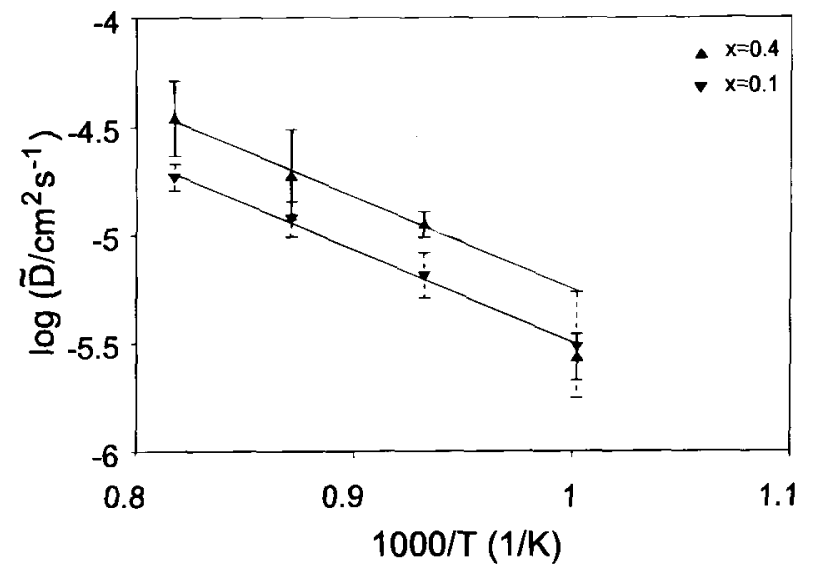

Fig. 6. Arrhennius plots of chemical diffusion coefficients.

talline dense membranes at $1273 \mathrm{~K}{ }^{1}$ The activation energies of $D_{\mathrm{v}}$ calculated from Table I are $74 \pm 12 \mathrm{~kJ} / \mathrm{mol}$ for $\mathrm{La}_{0.9} \mathrm{Sr}_{0.1} \mathrm{FeO}_{3-\delta}$ and $80 \pm 25 \mathrm{~kJ} / \mathrm{mol}$ for $\mathrm{La}_{0.6} \mathrm{Sr}_{0.4} \mathrm{FeO}_{3-\delta}$, in agreement with isotopic exchange data. ${ }^{21}$

Surface exchange coefficients.-In Fig. 7 the surface exchange coefficient, $K_{\mathrm{ex}}$, of $\mathrm{La}_{0.6} \mathrm{Sr}_{0.4} \mathrm{FeO}_{3-\delta}$ is shown $v$. oxygen partial pressure at several temperatures. Its value is proportional to $p_{\mathrm{O}}^{n}$, with $n=0.75$ to 0.83 . A similar dependency with $n=0.82$ to 0.95 was observed in the results of relaxation experiments on $\mathrm{La}_{0.9} \mathrm{Sr}_{0.1} \mathrm{FeO}_{3-\delta}$. In Fig. 8 and 9 the surface exchange coefficients $k_{\mathrm{O}}$ of both compositions, calculated with Eq. 23, are shown. At $p_{\mathrm{O}_{2}}=10^{-3.04}$ bar the activation energies are approximately $E_{\text {act }}=113 \pm$ $19 \mathrm{~kJ} / \mathrm{mol}$ for $x=0.1$ and $E_{\text {act }}=131 \pm 14 \mathrm{~kJ} / \mathrm{mol}$ for $x=$ 0.4 . The dependencies are slightly lower than for $K_{e x}$, with powers $n=0.75$ to 0.86 and $n=0.65$ to 0.84 for $x=0.1$ and $x=0.4$, respectively.

The exchange coefficients $k_{\mathrm{o}}$ reported for $x=0.1$ and $x=$ 0.4 at 0.065 bar $\mathrm{O}_{2}$ in the aforementioned study by Ishigaki et $a l .{ }^{21}$ are systematically smaller than those from the present study but are of the same order of magnitude. It should be noted that single crystals were used in the study by Ishigaki et al. The real surface area of an ideal single crystal is equal to its geometric surface area, which is the quantity used in calculation of the exchange coefficients. The real surface area of polycrystalline ceramics on a microscopic scale can be substantially larger.

The absolute values reported here are fairly close to isotopic exchange data reported by Carter et al., ${ }^{22}$ i.e., at $1073 \mathrm{~K}, k_{0}=2 \times 10^{-5} \mathrm{~cm} \mathrm{~s}^{-1}$ for $\mathrm{La}_{0.6} \mathrm{Ca}_{0.4} \mathrm{Co}_{0.8} \mathrm{Fe}_{0.2} \mathrm{O}_{3}$, and $k_{\mathrm{O}}=5 \times 10^{-6} \mathrm{~cm} \mathrm{~s}^{-1}$ for $\mathrm{La}_{0.8} \mathrm{Sr}_{0.2} \mathrm{CoO}_{3}$. A $p_{\mathrm{O}_{2}}$ dependency of $k_{\mathrm{O}}$ can be observed in results from thermogravimetric transient measurements on polycrystalline $\mathrm{La}_{0.7} \mathrm{Sr}_{0.3} \mathrm{CoO}_{3-\delta}{ }^{23}$ Reported values vary from $k_{\mathrm{O}}=8 \times 10^{-7} \mathrm{~cm} \mathrm{~s}^{-1}$ at $p_{\mathrm{O}_{2}}=$ $10^{-3.5}$ bar and $T=1093 \mathrm{~K}$ to $k_{0}=3 \times 10^{-5} \mathrm{~cm} \mathrm{~s}^{-1}$ in air at $1393 \mathrm{~K}$.

The $p_{\mathrm{O}_{2}}$ dependence of $k_{\mathrm{O}}$ can be used to infer the nature of the species involved in the rate-determining step of the surface reaction. The fact that $n \geq 0.5$ is a strong indication for the involvement of molecular oxygen. Selected

Table I. Chemical diffusion coefficients and oxygen vacancy diffusion coefficients in the oxygen partial pressure range 0.03 to 1 bar at various temperatures.

\begin{tabular}{rcccc} 
& $\begin{array}{c}x=0.1 \\
\log \tilde{D} \\
\left(\mathrm{~cm}^{2} \mathrm{~s}^{-1}\right)\end{array}$ & $\begin{array}{c}\log D_{\mathrm{v}} \\
\left(\mathrm{cm}^{2} \mathrm{~s}^{-1}\right)\end{array}$ & $\begin{array}{c}x=0.4 \\
\log \tilde{D}_{\mathrm{v}} \\
\left(\mathrm{cm}^{2} \mathrm{~s}^{-1}\right)\end{array}$ & $\begin{array}{c}\log D_{\mathrm{v}} \\
\left(\mathrm{cm}^{2} \mathrm{~s}^{-1}\right)\end{array}$ \\
\hline 998 & $-5.52 \pm 0.24$ & $-5.54 \pm 0.21$ & $-5.56 \pm 0.10$ & $-5.67 \pm 0.10$ \\
1073 & $-5.19 \pm 0.10$ & $-5.21 \pm 0.10$ & $-4.95 \pm 0.06$ & $-5.22 \pm 0.15$ \\
1148 & $-4.93 \pm 0.08$ & $-4.97 \pm 0.08$ & $-4.73 \pm 0.21$ & $-5.03 \pm 0.23$ \\
1223 & $-4.74 \pm 0.07$ & $-4.83 \pm 0.17$ & $-4.46 \pm 0.17$ & $-4.89 \pm 0.07$
\end{tabular}




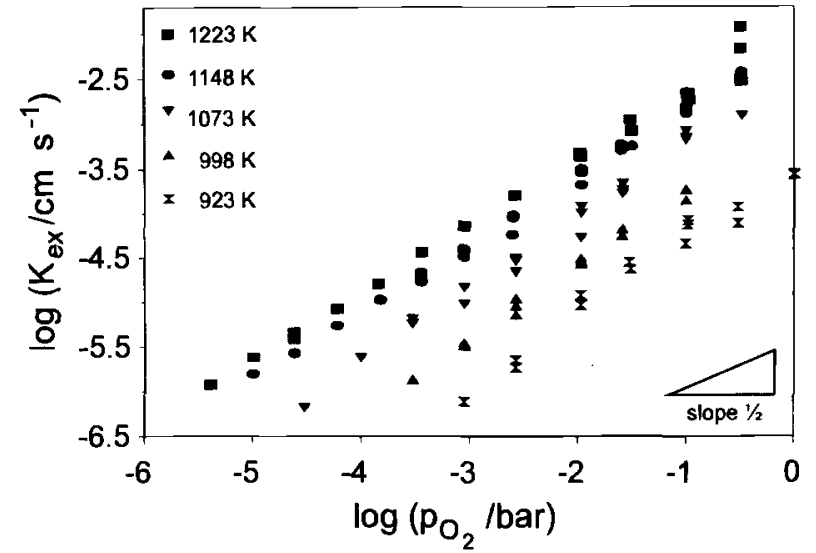

Fig. 7. Apparent surface exchange coefficients, $K_{\mathrm{ex}}$, of $\mathrm{La}_{0.6} \mathrm{Sr}_{0.4} \mathrm{FeO}_{3-8}$ vs. $\mathrm{P}_{\mathrm{O}_{2}}$ at several temperahures.

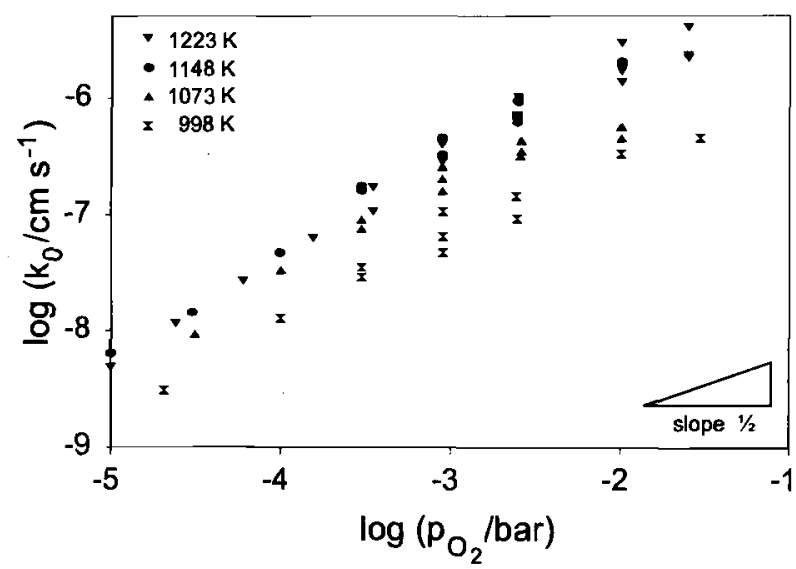

Fig. 8. Surface exchange coefficients, $k_{0}$, of $\mathrm{La}_{0.9} \mathrm{Sr}_{0.1} \mathrm{FeO}_{3-8} \mathrm{vs}$. $\mathrm{PO}_{2}$ at several temperahures.

reaction mechanisms were considered to explain the experimental data, and the most feasible ones are

Model $1 \quad \mathrm{O}_{2}+\mathrm{S} \rightleftarrows\left[\mathrm{S} \cdots \mathrm{O}_{2}\right] \quad k_{\mathrm{o}}=k_{1} p_{\mathrm{O}_{2}}$

Model $2 \quad \mathrm{O}_{2}+\mathrm{V}_{\mathrm{o}}^{\bullet \bullet} \rightleftarrows\left[\mathrm{V}_{\mathrm{o}}^{* \cdot} \cdots \mathrm{O}_{2}\right] \quad k_{\mathrm{O}}=k_{2} p_{\mathrm{O}_{2}}\left[\mathrm{~V}_{\mathrm{o}}^{\bullet \cdot}\right]$

Model $3 \quad \mathrm{O}_{2}+\mathrm{V}_{\mathrm{o}}^{\bullet}+e^{\prime} \rightleftarrows\left[\mathrm{V}_{\mathrm{o}}^{\bullet} \cdots \mathrm{O}_{2}\right] \rightleftarrows\left[\mathrm{V}_{\mathrm{o}}^{\bullet} \cdots \mathrm{O}_{2}^{-}\right]$

$$
k_{\mathrm{O}}=k_{3} p_{\mathrm{O}_{2}}\left[\mathrm{~V}_{\mathrm{o}}^{* \cdot}\right]\left[e^{\prime}\right]
$$

Model $4 \quad \mathrm{O}_{2}+\mathrm{V}_{\mathrm{o}} \cdot \mathrm{V}_{\mathrm{o}}^{\ddot{*}} \rightleftarrows 2\left[\mathrm{~V}_{\mathrm{o}}^{*} \cdots \mathrm{O}\right]$

$$
k_{\mathrm{O}}=k_{4} p_{\mathrm{O}_{2}}\left[\mathrm{~V}_{\mathrm{o}}^{\cdot \bullet}\right]^{2}
$$

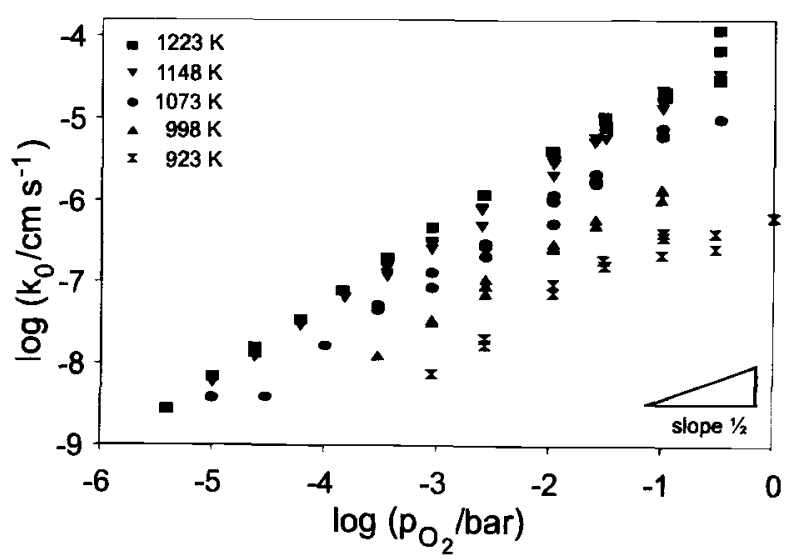

Fig. 9. Surface exchange coefficients, $k_{0}$, of $\mathrm{La}_{0.6} \mathrm{Sr}_{0.4} \mathrm{FeO}_{3-8} v s$. $\mathrm{PO}_{2}$ at several temperahures.
Since $k_{0}=r_{0} / c_{0}$, with $r_{0}$ the equilibrium oxygen exchange rate and $c_{0}$ the oxygen bulk concentration, possible expressions for $k_{\mathrm{o}}$ emerging from each model are also given.

The concentration of adsorption sites, $\mathrm{S}$, for oxygen is assumed to be large and independent of oxygen pressure in model 1 . In model 2 a surface oxygen vacancy acts as an adsorption site for molecular oxygen. Since the concentration of oxygen vacancies either increases or remains constant with decreasing oxygen pressure under all conditions, its pressure dependency $\left[\mathrm{V}_{\circ}^{*}\right] \sim p_{\mathrm{O}_{2}}^{m}$ has a power $m$ between $-1 / 2$ and $0 .{ }^{24}$ In model 3 , oxygen may adsorb either in neutral form on an F-center (a singly ionized surface oxygen vacancy) or in the form of $\mathrm{O}_{2}^{-25}$ on a doubly ionized vacancy. In model 4 two neighboring surface oxygen vacancies are involved.

Oxygen pressure dependencies of surface defect concentrations $\left[\mathrm{V}_{\mathrm{o}}^{\cdot \bullet}\right]$ and $\left[e^{\prime}\right]$ were calculated as discussed elsewhere, ${ }^{1}$ assuming that the same reactions determine the defect concentrations in the bulk and at the surface. ${ }^{2}$ Figures 10 and 11 show selected experimental data with the corresponding best fits derived from models 1 to 4 . As can be seen clearly in Fig. 10, reasonable agreement with experimental data is observed only for models 2 and 3 for $\mathrm{La}_{0.9} \mathrm{Sr}_{0.1} \mathrm{FeO}_{3-\delta}$.

The curves obtained from model calculations on $\mathrm{La}_{0.6} \mathrm{Sr}_{0.4} \mathrm{FeO}_{3-\delta}$, illustrated in Fig. 11, are much more alike than those on $\mathrm{La}_{0.9} \mathrm{Sr}_{0.1} \mathrm{FeO}_{3-\delta}$. Nevertheless, all models except for 2 and 3 deviate systematically from the experimental trends at high and/or low oxygen partial pressures. These results suggest that the rate-determining step on

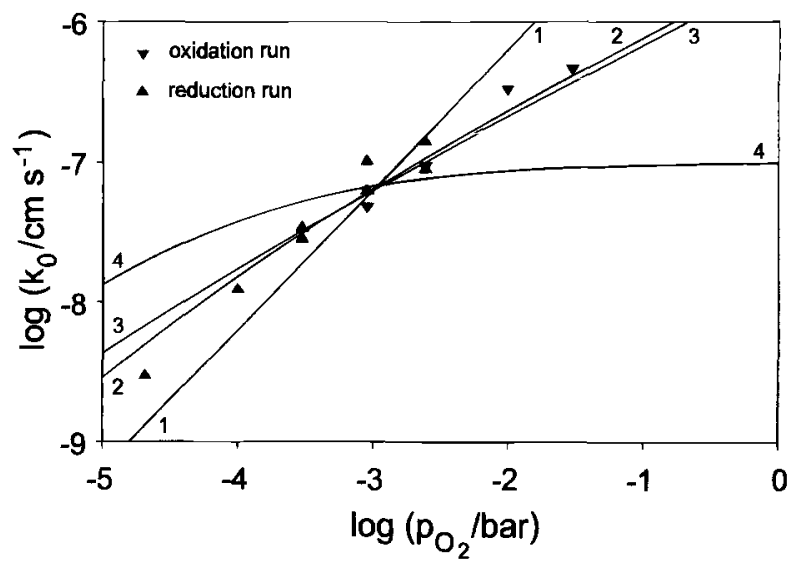

Fig. 10. Experimental and theoretical surface exchange coefficients of $\mathrm{La}_{0.9} \mathrm{Sr}_{0.1} \mathrm{FeO}_{3-8}$ at $998 \mathrm{~K}$. Numbers refer to the mechanisms described in the rext.

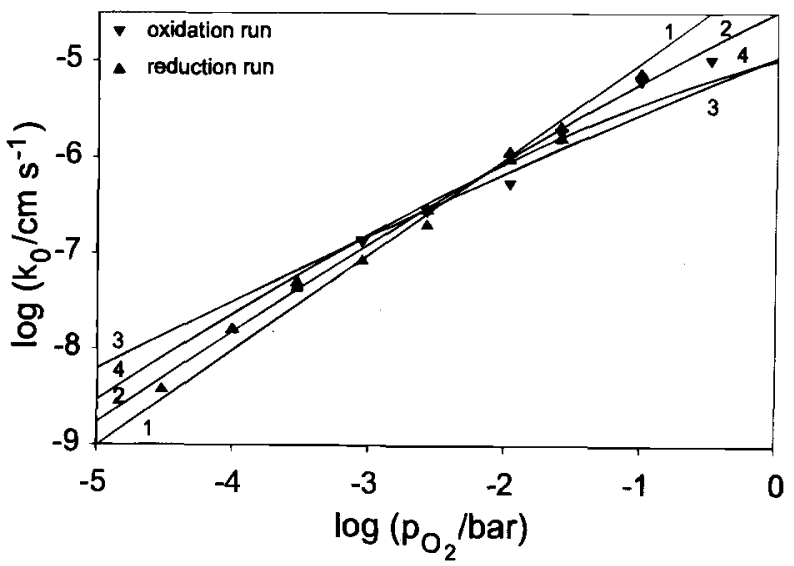

Fig. 11. Experimental and theoretical surface exchange coefficients $k_{0}$ of $\mathrm{La}_{0.6} \mathrm{Sr}_{0.4} \mathrm{FeO}_{3-8}$ at $1073 \mathrm{~K}$. Numbers refer to the mechanisms described in the text. 
both compositions can be described best by Eq. 26 or Eq. 27. In view of the small differences between the trends predicted by these two models, no conclusions can be drawn about the involvement of electronic species.

Mechanisms 2 and 3 both predict more or less linear relationships between the ratio $k_{\mathrm{o}} / p_{\mathrm{O}_{2}}$ and the oxygen vacancy parameter $\delta$. This is illustrated by data of $\mathrm{La}_{0.5} \mathrm{Sr}_{0.4} \mathrm{FeO}_{3-\delta}$ in Fig. 12. A linear-like correlation can be observed, which supports the current interpretation. Similar trends were seen in the results of $\mathrm{La}_{0.9} \mathrm{Sr}_{0.1} \mathrm{FeO}_{3-8}$. Table II lists the best fits of $k_{2}$ (Eq. 26) to the experimental data. Remarkably, the value of does not vary strongly with temperature for $x=0.1$, whereas it does for $x=0.4$.

The involvement of oxygen vacancies has already been proposed in the oxygen exchange process on $\mathrm{La}_{0.3} \mathrm{Sr}_{0.7} \mathrm{CoO}_{3-\delta}$. ${ }^{26}$ Using isotopic exchange a $p_{\mathrm{O}_{2}}^{n}$ dependency with $n=0.41 \pm 0.02$ was found for $k_{0}$, which was interpreted by assuming the rate-determining step to involve an adsorbed oxygen atom $\left(\left[\mathrm{O}_{\text {ads }}\right] \sim p_{\mathrm{O}_{2}}^{1 / 2}\right)$ and a surface oxygen vacancy $\left(\left[\mathrm{V}_{\mathrm{o}}^{*}\right] \sim p_{\mathrm{O} 2}^{-0.1}\right)$.

The indication of the direct involvement of oxygen vacancies in the surface exchange agrees with a suggestion by Kilner ${ }^{27}$ based on an observed relationship between $k_{0}$ and the oxygen tracer coefficient $D_{0}^{*}$ of different perovskite-type oxides. Since the value of $D_{0}^{*}$ is strongly correlated with the level of oxygen nonstoichiometry, a $\delta$ dependency can be predicted for $k_{\mathrm{O}}$.

\section{Conclusions}

It has been shown that transformation of the timedependent response of the electrical conductivity of thin specimens of $\mathrm{La}_{1-x} \mathrm{Sr}_{x} \mathrm{FeO}_{3-\delta}(x=0.1,0.4)$ to the frequency domain can yield information regarding the nature of the rate-determining step in the re-equilibration process after an abrupt change of the oxygen partial pressure in the ambient.

Diffusional control was observed at oxygen pressures of 0.03 to 1.0 bar $\mathrm{O}_{2}$. The chemical diffusion coefficients were found to be independent of the oxygen pressure, and for both investigated compositions the activation energy was about $80 \mathrm{~kJ} / \mathrm{mol}$. The oxygen vacancy diffusion coefficients calculated from these data are in good agreement with values known from literature.

At pressures below 0.01 bar $\mathrm{O}_{2}$, only exchange-controlled equilibration kinetics were seen. The absolute values of the apparent surface exchange coefficients were strongly dependent on the oxygen partial pressure. In conjunction with nonstoichiometry data from literature, the surface exchange coefficients, $k_{0}$, were calculated. They agreed reasonably well with values known from literature. The $p_{\mathrm{O}_{2}}$ dependencies of $k_{\mathrm{o}}$ were interpreted in terms of a rate-determining adsorption step involving at least an oxygen molecule and a vacant oxygen site at the surface.

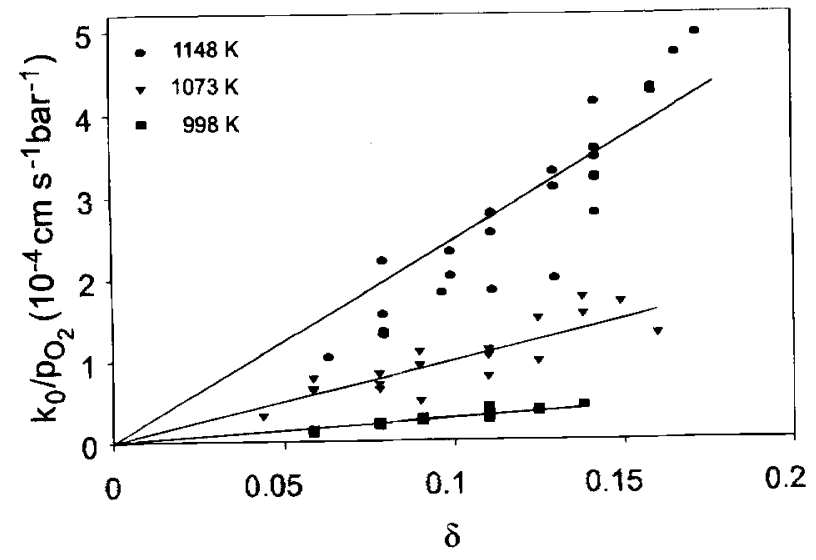

Fig. 12. Ratio $k_{0} / p_{\mathrm{O}_{2}}$ vs. the oxygen vacancy concentration, $\delta$, of $\mathrm{La}_{0.6} \mathrm{Sr}_{0.4} \mathrm{FeO}_{3-8}$.
Table II. Best fits of $k_{2}$ (Eq. 26) to the experimental data.

\begin{tabular}{rcc}
\hline$T(\mathrm{~K})$ & $\begin{array}{c}x=0.1 \\
\log k_{2}\left(\mathrm{~cm} \mathrm{~s}^{-1} \mathrm{bar}^{-1}\right)\end{array}$ & $\begin{array}{c}x=0.4 \\
\log k_{2}\left(\mathrm{~cm} \mathrm{~s}^{-1} \mathrm{bar}^{-1}\right)\end{array}$ \\
\hline 923 & & $-3.82 \pm 0.06$ \\
998 & $-1.80 \pm 0.10$ & $-3.55 \pm 0.08$ \\
1073 & $-1.74 \pm 0.23$ & $-3.00 \pm 0.04$ \\
1148 & $-1.62 \pm 0.07$ & $-2.61 \pm 0.03$ \\
1223 & $-1.80 \pm 0.05$ & $-2.49 \pm 0.03$
\end{tabular}

The apparent activation energies of $k_{0}$ vary between 110 and $140 \mathrm{~kJ} / \mathrm{mol}$ for both compositions.

\section{Acknowledgments}

B. A. Boukamp is gratefully acknowledged for many useful discussions. G. Mollenhorst is gratefully acknowledged for the design of the quartz reactor.

Manuscript submitted Sept. 23, 1996; revised manuscript received Dec. 11, 1996.

The authors assisted in meeting the publication costs of this article.

\section{REFERENCES}

1. J. E. ten Elshof, H. J. M. Bouwmeester, and H. Verweij, Solid State Ionics, 81, 97 (1995).

2. J. E. ten Elshof, H. J. M. Bouwmeester, and H. Verweij, ibid., 89, 81 (1996).

3. I. Yasuda and T. Hikita, This Journal, 141, 1268 (1994).

4. J. Mizusaki, M. Yoshihiro, S. Yamauchi, and K. Fueki, J. Solid State Chem., 58, 257 (1985).

5. F. A. Kröger, The Chemistry of Imperfect Crystals, North-Holland, Amsterdam, (1964).

6. Y. Denos, F. Morin, and G. Trudel, in Ionic and Mixed Conducting Oxides, PV 94-12, T. A. Ramanarayanan, W. L. Worrell, and H. L. Tuller, Editors, p. 150, The Electrochemical Society Proceedings Series, Pennington, NJ (1994).

7. I. Yasuda and M. Hishinuma, Solid State Ionics, 80, 141 (1995).

8. C. J. Yu, D. M. Sparlin, and H. U. Anderson, J. Am. Ceram. Soc., 70, C189 (1987).

9. B. Ma, U. Balachandran, J.-H. Park, and C. U. Segre, Solid State Ionics, 83, 65 (1996).

10. J. Nowotny and A. Sadowsky, J. Am. Ceram. Soc., 62, $24(1979)$.

11. F. Morin and R. Dieckmann, Z. Phys. Chem. Neue Folge, 129, 219 (1982).

12. J. Nowotny, J. Oblakowski, A. Sadowski, and J. B. Wagner, Jr., Oxid. Met., 14, 437 (1980).

13. J. Crank, The Mathematics of Diffusion, 2 nd ed., Clarendon Press, Oxford (1979).

14. V. Doví, F. Gesmundo, and F. Viani, Oxid. Met., 23, 35 (1985).

15. F. Gesmundo, F. Viani, and V. Doví, ibid., 23, 141 (1985).

16. F. Morin, This Journal, 128, 2439 (1981).

17. F. Morin, React. Solids, 7, 307 (1989).

18. H. Schmalzried, Solid State Reactions, 2nd ed., Verlag Chemie, Weinheim-Deerfield Beach-Basel (1981).

19. H. Deng, M. Zhou, and B. Abeles, Solid State Ionics, 74, 75 (1994).

20. B. A. Boukamp, Equivalent Circuit, 2nd ed., University of Twente, Enschede, The Netherlands, (19881989).

21. T. Ishigaki, S. Yamauchi, K. Kishio, J. Mizusaki, and K. Fueki, J. Solid State Chem., 73, 179 (1988).

22. S. Carter, A. Selcuk, R. J. Chater, J. Kajda, J. A. Kilner, and B. C. H. Steele, Solid State Ionics, 53-56, 597 (1992).

23. O.F. Kononchuk, D. P. Sutija, T. Norby, and P. Kofstad, in Solid Oxide Fuel Cells, PV 95-1, M. Dokiya, O. Yamamoto, H. Tagawa, and S. C. Singhai, Editors, p. 395, The Electrochemical Society Proceedings Series, Pennington, NJ (1995).

24. J. E. ten Elshof, H. J. M. Bouwmeester, and H. Verweij, Appl. Catal. A, 130, 195 (1995).

25. M. Che and A. J. Tench, in Advances in Catalysis, Vol. 31, p. 1, Academic Press, New York (1983). 
26. R. H. E. van Doorn, Ph.D. Thesis, University of Twente, Enschede, The Netherlands (1996)

27. J. A. Kilner, in Ionic and Mixed Conducting Oxides,
T. A. Ramanarayanan, W. L. Worrell, and H. L. Tuller, Editors, PV 94-12, p. 174, The Electrochemical Society Proceedings Series, Pennington, NJ (1994).

\title{
Characterization of AuGe- and AuTe-Based Ohmic Contacts on InAs n-Channel High Electron Mobility Transistors
}

\author{
Y. Zhao, M. J. Jurkovic, and W. I. Wang* \\ Department of Electrical Engineering, Columbia University, New York, New York 10027, USA
}

\section{ABSTRACT}

Transmission line measurements performed on $\mathrm{AlSb} / \mathrm{GaSb}$ heterostructure buried InAs n-channels incorporating $\mathrm{AuGe}-$ and AuTe-based ohmic contacts show that the optimum contact resistance for $\mathrm{Ni} / \mathrm{AuGe} / \mathrm{Ni} / \mathrm{Au}$ metallization is achieved at $325^{\circ} \mathrm{C}$ for a $20 \mathrm{~s}$ annealing process $\left(\rho_{\mathrm{c}}=2.3 \times 10^{-7} \Omega \mathrm{cm}^{2}\right.$, a record low for an AlSb/GaSb structure), whereas only $1.3 \times 10^{-6} \Omega-\mathrm{cm}^{2}$ is obtained for the $\mathrm{Ni} / \mathrm{AuTe} / \mathrm{Ni} / \mathrm{Au}$ system optimally annealed at $400^{\circ} \mathrm{C}$. Uniform alloyed surface morphology is observed in $\mathrm{Ni} / \mathrm{AuGe} / \mathrm{Ni} / \mathrm{Au}$ contacts, while the blistered surface appearance of the $\mathrm{Ni} / \mathrm{AuTe} / \mathrm{Ni} / \mathrm{Au}$ system correlates with degraded performance. Measured dc and microwave characteristics of $1 \mu \mathrm{m}$ gate length InAs n-channel high electron mobility transistors using AuGe- and AuTe-based source/drain contacts show that ohmic contact quality is critical to device performance.

\section{Introduction}

Methods of ohmic contact fabrication on III-V semiconductors have been extensively investigated due to the critical effect of contact quality on device performance. Contacts to GaAs- and InP-based devices have been well characterized, ${ }^{1,2}$ while contact formation to InAs/AlSbbased high electron mobility transistors (HEMTs) remains a critical limitation to device performance due to the reduced ratio of channel conductivity to contact conductivity in such devices. ${ }^{3-5}$ Although a number of studies have focused on ohmic contacts to $n-$ and p-GaSb, ${ }^{6-9}$ no data has been presented to justify the use of AuGe/Ni alloy in InAs/AlSb-based n-channel HEMTs. AlSb is known to dominate contact characteristics, as very thin $\mathrm{GaSb}$ and In As top layers are used for surface leakage reduction in such AlSb barrier structures. ${ }^{4}$

In this work, ohmic contacts directly to AlSb/GaSb barrier, InAs n-channel heterostructures using $\mathrm{Ni} / \mathrm{AuGe} /$ $\mathrm{Ni} / \mathrm{Au}$ and $\mathrm{Ni} / \mathrm{AuTe} / \mathrm{Ni} / \mathrm{Au}$ metallizations are characterized by transmission line measurement (TLM). In addition, dc and microwave measurements are performed on similarly metallized HEMTs in order to correlate device performance with source/drain ohmic contact characteristics.

\section{Experimental}

Samples (shown in Table I) similar to conventional InAs heterostructure field effect transistor (HFET) structures were grown by molecular beam epitaxy (MBE) on semiinsulating (100)-oriented InP substrates. The growth temperature was $500^{\circ} \mathrm{C}$ for the buffer layers and $470^{\circ} \mathrm{C}$ for the InAs channel and gate barrier layers. The InAs channel was Si-doped in order to eliminate inaccuracies in ohmic contact parameter measurement arising from fluctuation in the two-dimensional electron gas (2DEG) concentration. An unintentionally doped (AlSb) ${ }_{m}(\mathrm{GaSb})_{n}$ short period superlattice (SPS) barrier was used in order to enhance gate performance in the InAs HFETs. ${ }^{10}$ The ${ }^{+}$Si-doped InAs cap layer serves to protect the AlSb/GaSb structure from etch-attack during lithography as well as to decrease the contact resistance by way of barrier height reduction.

TLM mesas were defined by wet chemical etching $\left(\mathrm{H}_{3} \mathrm{PO}_{4}: \mathrm{H}_{2} \mathrm{O}_{2}: \mathrm{H}_{2} \mathrm{O}=5: 3: 100\right.$ for $\left.60 \mathrm{~s}\right)$ down to the unintentionally doped $\mathrm{Al}_{0.7} \mathrm{Ga}_{0.3} \mathrm{Sb}$ buffer. The ohmic contact patterns were then formed using standard photolithography and lift-off techniques. The contact metallization for each sample was fabricated using a conventional multiple

* Electrochemical Society Active Member. source metal evaporation system at pressures below $1 \times$ $10^{-6}$ Torr. The evaporation sequence for the AuGe eutecticbased contacts were: $8 \mathrm{~nm} \mathrm{Ni}, 100 \mathrm{~nm}$ AuGe eutectic (88:12 AuGe weight percentage (w/o) composition), $20 \mathrm{~nm} \mathrm{Ni}$, and $100 \mathrm{~nm} \mathrm{Au}$. AuTe eutectic-based metallization was similarly implemented: $8 \mathrm{~nm} \mathrm{Ni}, 100 \mathrm{~nm}$ AuTe eutectic (97:3 AuTe w/o composition), $20 \mathrm{~nm} \mathrm{Ni}$, and $100 \mathrm{~nm} \mathrm{Au}$. Finally, after selectively etching the n-doped InAs cap layer in the spaces between the metallic contacts, thus reducing surface leakage, rapid thermal annealing (RTA) was performed in a Heatpulse 210 system at temperatures ranging from 300 to $475^{\circ} \mathrm{C}$ for $20 \mathrm{~s}$ in a forming gas ambient $\left(5 \% \mathrm{H}_{2}, 95 \% \mathrm{~N}_{2}\right)$ with $30 \mathrm{sccm}$ flow.

The measured contact resistance $\left(R_{c}\right)$ and specific contact resistance $\left(\rho_{c}\right)$ determined by means of TLM ${ }^{11}$ combined with a four-point probe method included the series resistance contribution of the undoped gate barrier layers. The spacings of the contact stripes were measured by a calibrated optical microscope. A linear regression of contact spacing was used $(2,3,5,9,12$, and $15 \mu \mathrm{m})$ in the TLM analysis, and more than 20 devices of each type were measured.

In order to study the effect of the ohmic contact quality on device performance, HEMTs with undoped InAs channels (as shown in Table I) with a gate size of $1 \times 25 \mu \mathrm{m}$ and source/drain contacts spaced $3 \mu \mathrm{m}$ apart were fabricated incorporating optimally annealed AuGe- and AuTe-based metallization. Device fabrication was similar to that for the TLM test structure except that an InAs channel sidewall recess was performed prior to source/drain metallization, and annealing was followed by a $150 \mathrm{~nm}$ Au-recessed

Table I. The layer structures used for the study of ohmic contacts and InAs n-channel HEMTs.

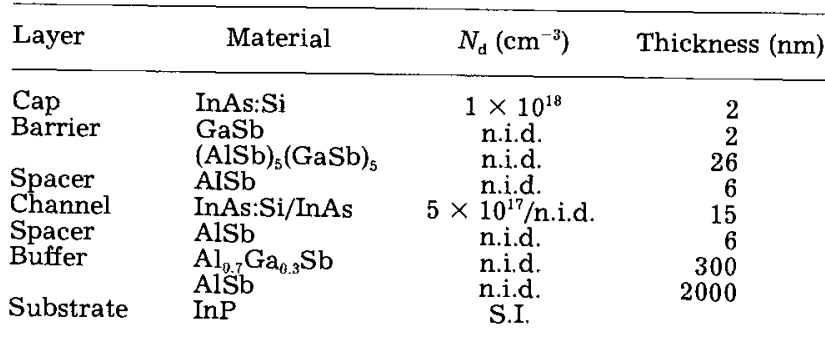

n.i.d. = nonintentially doped.

S.I. = Semi-insulating. 